STUDI

FRANCESI

\section{Studi Francesi}

Rivista quadrimestrale fondata da Franco Simone

166 (I | LVI) | 2012

Varia

\title{
Laurent Bove, Vauvenargues ou le séditieux. Entre Pascal et Spinoza. Une philosophie pour la seconde nature
}

Peter Balazs

\section{(2) OpenEdition}

Journals

Édition électronique

URL : https://journals.openedition.org/studifrancesi/4700

DOI : 10.4000/studifrancesi.4700

ISSN : 2427-5856

Éditeur

Rosenberg \& Sellier

Édition imprimée

Date de publication : 1 avril 2012

Pagination : 153

ISSN : 0039-2944

\section{Référence électronique}

Peter Balazs, «Laurent Bove, Vauvenargues ou le séditieux. Entre Pascal et Spinoza. Une philosophie pour la seconde nature », Studi Francesi [En ligne], 166 (I | LVI) | 2012, mis en ligne le 30 novembre 2015, consulté le 22 novembre 2021. URL : http://journals.openedition.org/studifrancesi/4700 ; DOI : https://doi.org/10.4000/studifrancesi.4700

Ce document a été généré automatiquement le 22 novembre 2021.

\section{c) (†) $९$}

Studi Francesi è distribuita con Licenza Creative Commons Attribuzione - Non commerciale - Non opere derivate 4.0 Internazionale. 


\title{
Laurent Bove, Vauvenargues ou le séditieux. Entre Pascal et Spinoza. Une philosophie pour la seconde nature
}

\author{
Peter Balazs
}

\section{RÉFÉRENCE}

LAURENT BOVE, Vauvenargues ou le séditieux. Entre Pascal et Spinoza. Une philosophie pour la seconde nature, Paris, Honoré Champion, 2010, pp. 328.

Dans l'«Introduction», dans laquelle on trouve une biographie de Vauvenargues et l'histoire (tourmentée) des éditions de son œuvre, le lecteur voit déjà se dessiner l'image d'un philosophe spinoziste de la nécessité. Ce déterminisme métaphysique fondamental, le trait central de la philosophie de Vauvenargues, est l'élément qui permet à Laurent Bove de le ranger parmi les représentants des Lumières radicales. La première partie de l'ouvrage, intitulée "Le "spinozisme" de Vauvenargues», s'efforce d'éclairer le sens fondamental des concepts vauvenarguiens tels que puissance d'agir, vertu, amour de l'être (il s'agit surtout de son Traité sur le libre arbitre et de son Discours sur la liberté). L'étude de ces ouvrages permettent d'établir en quoi cette métaphysique de puissance et de nécessité est l'héritière de celle de l'auteur de l'Éthique (et ceci malgré le fait que le nom de Spinoza n'apparaît que rarement dans ce corpus). La deuxième partie, intitulée «Politiques de la seconde nature», examine l'omniprésence de Pascal dans la pensée politico-historique de Vauvenargues. Les principes essentiels de la conception politique commune à ces deux auteurs sont la coutume, la force, l'intérêt. Mais Vauvenargues ne manque pas de tourner ces concepts pascaliens contre le projet apologétique de l'auteur des Pensées: vu de cette perspective, l'état actuel du peuple juif n'est point une preuve de la vérité de la religion chrétienne, mais bel et bien la conséquence de l'oppression exercée par d'autres peuples à leurs dépens avant et après l'apparition du Christ! Dans cette deuxième partie, on trouve aussi un chapitre consacré à l'attitude philosophique fondamentalement anti-platonicienne de 
Vauvenargues: il se met en opposition brutale avec des «faux philosophes», penseurs de métier, enfermés dans leur cabinet et leurs préjugés idéalistes et humanistes. Les héros intellectuels de Vauvenargues sont les vrais philosophes, nourris du réel et de la connaissance pratique des hommes, tels Machiavel et Spinoza. La naïveté que Vauvenargues reproche aux idéalistes n'est autre que de croire au finalisme universel et en un libre arbitre que nous posséderions pour choisir librement le bien, sur son modèle transcendant.

2 La troisième partie de l'ouvrage, intitulée «De la génération de l'être: familiarité et conciliation» traite l'aspect non plus critique, mais constructif de la pensée de Vauvenargues: il s'agit de montrer comment l'auteur en question s'efforce de défendre, au siècle caractérisé par le double "nihilisme" du dogmatisme et du pyrrhonisme, la vivante vertu dont l'effectivité réussit à vaincre toute sorte de satire. Enfin, la partie conclusive de l'ouvrage, intitulée «Entre Pascal et Spinoza. Du libertinage vers la liberté commune», revient sur les effets philosophiques de la rencontre des deux logiques - de la puissance productive et de la seconde nature - que Vauvenargues se propose de concilier dans un système philosophique nouveau, ontologiquement fondé, déterministe, mais non point fataliste et enfin articulant la sédition intellectuelle et individuelle à une sédition sociale. 